\title{
Implementing Automated Quality Management Software System through Total Quality Management and Knowledge Management Concepts to Improve the Quality of Education in the Universities
}

\author{
Tasneem F. Alfalah ${ }^{1}$, Salsabeel F. Alfalah ${ }^{2}$ \& Jannat F. Falah ${ }^{2}$ \\ ${ }^{1}$ Department of Management, Applied Science Private University, Amman, Jordan \\ 2 Department of Computer Information System, the University of Jordan \\ Correspondence: Tasneem F. Alfalah, Department of Management, Applied Science Private University, Amman, \\ Jordan. E-mail: tasneem_alabady@hotmail.com
}

Received: March 14, 2017

doi:10.5539/ijbm.v12n5p145

\begin{abstract}
Document archiving is very important in any large educational institution, as they contain information that is critical and affects quality management as well as knowledge management. The purpose of knowledge management and information systems is to organize the intellectual capital of the universities in a formally structured way for easy use and help managers make better decisions in all areas. Thus, the sources of competitive advantage in universities derive from intellectual capital and innovations. In addition, the path to a competitive advantage comes from the ability to manage knowledge to create quality of knowledge. Quality and knowledge are good indicators with which to measure a university's overall competitiveness. This research illustrates the importance of knowledge management in universities and the role of the Information Technology (IT) in facilitating, sharing and accelerating growth of knowledge, in addition to improving the quality of education level in the university. The research also describes both the conceptual and the empirical frame work of a Quality management automated system. We expect this approach to noticeably reduce the cost in the faculties in the University of Jordan, and prevent all the disadvantage of the current situation and improve the quality of education.
\end{abstract}

Keywords: information systems, knowledge management, quality management

\section{Introduction}

This research demonstrates the importance of knowledge management in educational institutions and how knowledge management can best obtained by correlating it with information technology systems. Thus creating quality of knowledge helps in creating a new knowledge as well as transferring it by developing a computerized system to archive essential documents, which will enhance quality. The remainder of this research is structured as follows: section two "Background" reviews the existing literature relating to Knowledge Management Systems, Information System, and Quality Management and the relationship between them. Section three consists of four parts, the first part provides a detailed description of the Problem definition and Current Situation, the second is both the conceptual and the empirical frame work of the automated system, the third and fourth parts are "Proposed system, its objectives, and expected results of the project" and "Practical steps for system implementation", respectively. Section four is the evaluation which talks about the limitations of using knowledge management system and observations and discussions. The last section is the conclusion and contribution to knowledge.

\section{Research Background}

\subsection{Knowledge Management}

In the middle of 1980's organisations started to rely on the important fact of knowledge in a competitive market; however, only in the middle of 1990's knowledge management started to take a place in organizations management and in academic field with the aim to create and transfer knowledge if possible within the available resources(Wiig, 1997). Also, soon after the information era, organizations started to realise that it would not be enough to collect information and build a large information system, but that the real needs is to build a system to 
help manager to understand and to emphasise knowledge management in their management (Adams \& Mouatt, 2010; Jashapara, 2005)(Gordon \& Grant, 2004) to enable the creation of knowledge ( Takeuchi \& Nonaka, 1995), share it (Lin, 2008; Brown \& Duguid, 2001), and to manage it (Hazlett, 2005). Some organizations such as Apple (Moon \& Desouza, 2010), Google (Smith \& Paquette, 2010), Shell and BP (Carrillo, 2004) took a further step and structured their organizations strategy based on knowledge management models and techniques. Knowledge starts as data, combining data to become information, information becomes knowledge when it is processed and analysed (Rowley and Jennifer, 2007) through knowledge management. Knowledge management is about replacing existing knowledge with new developed knowledge and supporting creativity and innovation (Alavi et al., 2001).This is achieved through people communication and information flow (Alavi et al., 2001). Nevertheless, it is not a simple process due to the fact that organizations usually do not know what information they have, in addition to having systems that are not efficient in retrieving the information/knowledge that resides in the input data (Huber, 1991). Accordingly using information systems will help to retrieve accurate and needed knowledge which will enhance the quality of work.

Knowledge management is an essential part of any organization; it facilitates utilizing and deploying knowledge management functions in an effective way, and results in quality of knowledge that has a huge contribution in decision making and problem solving (Tongchuay et al, 2008). Consequently, knowledge management performance can measure by knowledge quality (Tongchuay et al, 2008).

\subsection{Information System}

Building information system in the organization is a fundamental and basic requirement of quality management (NELSON et al, 2005), through which IT systems increase speed, accuracy and efficiency (Becerra-Fernandez et al. 2004). Juha and Ismo (2002) illustrate that developing an appropriate IT system will integrate quality management for the organization and become an efficient management. Furthermore executing IT system will provide preservation and archiving of the data, thus the security will increase. Additionally quality management should include and involve all the users in the organization "date, supervisor, designer, manager and so on" that are in the templates generated by the IT system (Juha \& Ismo, 2002)

Information is the output of an input set of data that has gone on certain processes, manipulations and procedures making the use of it meaningful to the receiver [4]. Hence, creating knowledge using an IT based system enables storing data in an organized way, retrieving it whenever needed, and allows for consistent data mining that predicts information from the databases whether for the present time or for the future. Although, the IT based system is a vital enabler for knowledge management, it does not resolve all knowledge management problems (Alavi et al., 2001). The IT software system can help you develop, implement and maintain a management system confirming to ISO9001 and ISO14001 and replace the bulk of paper record with space-saving and environment-friendly.

\subsection{Quality Management}

Higher education is a dynamic and vital service industry with huge competition and growth all over the world; however increased responsibility is frequently cited as a rationale for a greater emphasis on quality (Oldfield \& Baron, 1998; Brookes and Becket, 2006). The quality of higher education as a service is also fundamental to a country's development because universities prepare the professionals who will work as managers in companies and manage public and private resources and care for the health and education of new generations (Oliveriav \& Ferreira, 2009). Every institution has to plan a quality system to measure and improve overall university quality. Continual improvement is an internal/external process, which has to be implemented in universities and higher education institutions (Dolinsek, ), moreover quality is not just for manufactures, quality tools and procedures help the universities (colleges and professors) to continually improve the way of teaching and learning and provide wide services that enhance the quality of knowledge therefore the quality of education. Cheung and Duan (2014) recommended in their study in the school of public health in University of Columbia in New York, that if the organization followed a frame work of quality improvement it will reduce the cost associated with poor quality. However quality of management systems improves the quality of projects design thus reduces design faults (Cornick, 1988) (Lukasz, 2012). Brookes and Becket (2008) determine the core elements of the best quality model of education which needs to improve the quality of education these elements are, "universities must focus on the transformation of learners, which enhances them through adding value to their capabilities, synergistic collaboration at the learning interface and senior management that encourages and ensures a collegial culture". 


\subsection{Relationship between Quality Management, Knowledge Management and IT System}

Universities are a systematic configuration of employees to achieve the universities aims. To obtain the competitive advantages and achieve the desired aims a university must apply and use the management tools such as knowledge management and quality management (Hung et. al, 2010;

2013). Quality management approaches emphasize scientific approaches, formal knowledge processing, statistical analysis, matrices and measurements to integrate and design a quality system. Using technology particularly IT tools and techniques to prevent errors from occurring and before knowledge is applied will help in improving the quality of work in any organization (Goetch \& Davis, 2007). Additionally, Hung et al. (2010) exposed that applying knowledge management and quality management will lead to improve the quality of process as well as performance which will satisfy customer needs. Following them, Zetie (2002) illustrate that adopting quality management and knowledge management has both theoretical and practical significance. In addition implementing knowledge management in any organizations will help to become more innovative, creative, efficient and increase the organization's performance (Gold et al. 2001; Zack et al. 2009), which are the same key elements of quality management. Moreover the IT software system will help to facilitate and achieve these requirements. All the previous studies illustrate that there is a strong relationship between implementing knowledge management and quality management and there are a similar outputs when any of them are implemented in any organization.

\section{Aim and Objectives}

The aim of this research is to critically evaluate the potential contribution of knowledge management, quality management and IT software systems in improving quality of education for the University of Jordan through implementing automated quality management software system.

In order to achieve this aim, the following objectives have been set:

1. Critically assess the development of IT software system, knowledge management, and quality management towards achieving quality of education by thorough examination of literature review,

2. Develop a hybrid model to determine the needs of university faculty members,

3. Determine the systems functional requirements and non-functional requirements based on faculty members requirements,

4. Develop the system to apply the concept of quality management and knowledge management,

5. Develop the automated system to make the archiving system process easier and meet the knowledge management and quality management standards.

\section{Problem Definition and Current Situation}

Increasing competition between universities, and the great expectation and diversity of students as consumers forced the universities to improve their level of education and knowledge system by applying the concepts and practices of quality management (Becket \& Brookes, 2008). Moreover the competition between universities is increasing across national borders (Brookes \& Becket, 2007), these forces request that quality management and knowledge management clearly become valued requirements, to improve the quality of education in the university. Implementing IT software system will help the university to meet these requirements. To implement the IT system the first stage was assessment of the current system which is used in the university. Table 1 illustrates the disadvantages of the current system and a clear explanation for each stage. The system will allow users to edit information fields directly, data can easily transmitted and retrieved, faster data access that will increase productivity for workers. Replacing paper-based quality management automated system with automated quality software and that will improve the quality standards and knowledge management requirements, further decreasing time and cost when producing statistical reports.

\section{Conceptual Research Model}

Below is a representation of the conceptual research model in Figure1, which explores the relationship between the research variables knowledge management, IT system and quality management.

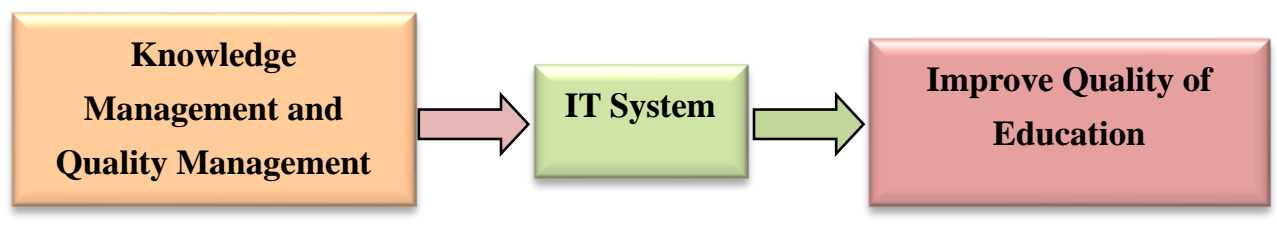


Figure 1. Proposed research model

The conceptual model of this research is based on the theoretical background and the literature review which indicated the relationship between and knowledge management, IT software systems and quality management in improving quality of education. This model will examine the role of using IT software systems to facilitate sharing and acceleration growth of knowledge additionally improve the quality of education level in the university. The proposed model will enhance the way managers and academic staffs in the university think of automated quality management software system, in relation to meeting the quality requirements to improve the quality level of the education in the university. The contribution of the present research will be an increase in awareness of the importance of implementing this model in the universities to meet knowledge management requirement to improve quality level of the academic staff therefor improving education quality.

\section{Emprical Research Methodology Design}

The present research can be categorized as applied research according to its purpose and context (Saunders et al., 2012). In this research the adopted approach is the deductive research approach. The research started by ideas developed from academic literature and examination, then tested. This involved testing of the theoretical scheme by using a research strategy designed for this purpose using (Interview and questionnaire) in data collection and testing stages. In this research study, mixed methods were used in the different stages of the research, and both quantitative and qualitative research methods were combined together in the research design. This is known as mixed methods research, i.e.: "empirical research that involves the collection and analysis of both qualitative and quantitative data" (Punch, 2009:288).

\subsection{Data Collection and Study Poulation}

The interview was for the stakeholder (administrator, dean, department head and faculty members). The interview covers three main types of questions; the first one was related to problems in the current archiving system, then questions related about the expected system including the archiving, retrieving, expected tools, reports, etc. then questions related to stakeholders (administrator, dean, department head and faculty members) and how the system will affect the knowledge management and enhance the quality in the university. The questionnaire used to get the feedback from the stakeholder for the system and define the requirements to be done in the future work. The questionnaire includes two main types of questions, the first one related to system design, the other related if the system enhanced the quality standards and knowledge management attributes.

\section{Results Discussion}

As shown in Table 1, the interview was held at the University of Jordan in Amman, Jordan, the time with each group was limited to 1 hour. The focus groups consisted of: (1) Administrator, (2) dean, and (3) department head and (4) faculty members.

Table 1. Focus group for this research

\begin{tabular}{ll}
\hline Focus Groups in the University of Jordan & Number \\
\hline Administrator & 3 \\
Dean & 1 \\
Department head & 5 \\
Faculty members & 15 \\
Total & 24 \\
\hline
\end{tabular}

Each group met separately and were asked and discuss the problems that facing them in saving, retrieving and monitoring the course files and determine what they using in the file archiving and if it is an efficient, and what the expectation from the new system. Further the group define how the system will enhance the quality and knowledge management attributes.

The questionnaire was used to get the feedback from the stakeholder about the system. This phase was an evaluation conducted to provide information about the quality of the system which is being developed. It is the process of verifying and validating that an application is working as expected and satisfies both functional and non-functional requirements as shown in Table 2. 
Table 2. The Percentages of the answer questions

\begin{tabular}{lccc}
\hline \multicolumn{1}{c}{ Questions } & Yes & No & Yes (Percentages) \\
\hline Do you think that the design is easy to use & 55 & 5 & 91.6 \\
Do you think that the design is intuitive & 53 & 7 & 88.3 \\
Do you think that the design is functional and usable & 57 & 3 & 95 \\
Do you think that the website enhanced the archiving information process & 55 & 5 & 91.6 \\
(members and courses) & & 2 & 96.6 \\
Did the website solve the problems you were facing in monitoring and retrieving course details and & 58 & 2 & 86.6 \\
members information & 52 & 8 \\
Will you support the decision to develop the website in the future & 50 & 10 & 83.3 \\
Do you think that the alerts that appear in your reports are helpful for you & 56 & 4 & 93.3 \\
Do you think if this website applied in the facultyand will enhance the quality & & $\mathbf{9 0 . 8}$ \\
Overall Mean for yes answers & &
\end{tabular}

Table 2 illustrates the percentages of the results of the questionnaire which was used to get the feedback about the system, the 'yes' percentage for all the questions higher than the 'No', that means that the level of the satisfaction was very high and the stakeholder were satisfied.

The automated quality management system aims to overcome the aforementioned issues, and provided the university with the tools to streamline the end-to-end quality management process. With automated change control, the dean, head of departments and dean assistants have visibility into the status of any change request see Appendix A. And all actions are tracked automatically by the system. Also databases allow users to edit information fields directly, store information digitally, which will be in a form that can be easily transmitted, instantaneous access to information, faster data access time can increase the productivity for workers who use data on a regular basis and systematic organizing, tracking, storing and retrieving of documents and files. This systematic approach will be guided by specific standards, replacing paper-based quality management systems with automated quality management software systems will noticeably improve the university's ability to comply with regulations and quality standards, Produce high quality reports and statistics quickly and at the lowest possible cost, and auto reminders can be provided for: filling in required forms, update information, and submit reports, etc.

This system requires an input of explicit knowledge such as grades, syllabus, and evaluation of each course in every semester...etc. The output is tacit knowledge organized and represented after some data processes. Now knowledge is well managed and has a positive impact on the academic institute when it is deployed properly. These facilitate sharing and accelerating growth of knowledge.

\section{Conclusion and Contribution to Knowledge}

While there are still several limitations of the knowledge management and quality management besides that it is not fully applied in all the faculties, this paper aimed to illustrates the importance of knowledge management and quality management in the universities and the role of the IT system in facilitating and achieving it. Moreover, it emphasizes all the advantages of using it comparing to an existing paper based system. It is important because it is a key to enable a quality of knowledge to be created and transferred in a convenient approach. In addition, the significance of knowledge management comes when professors know the strengths and weaknesses -whether in their teaching and delivering a new knowledge to students or in their way of assessing the students-through the information and the analysis that is done by the knowledge management system. The criteria for contribution to knowledge of this research can be measured in terms of developing an innovative process and automotive quality management system to deploy and improve the quality of service and education level in universities. The benefit of using this process and system are the following:

$>$ Enhance the way universities mangers think of any services industry in relation to meeting Faculty member requirements

$>$ Facilitate knowledge sharing and knowledge management

> Improve their Universities" quality and user satisfaction 
$>$ Focus on ranking the most important customers' requirements from a customer's point of view and managerial point of the view

$>$ Determine the appropriate functional requirements for every users' requirements

$>$ Cutting the cost in the Faculty

$>$ Prevent all the disadvantage of the current situation.

\section{References}

Aas, E. J. (2000). Design Quality and Design Efficiency; Definitions, Metrics and Relevant Design Experiences. Quality Electronic Design, ISQED 2000, Proceedings IEEE 2000 First International Symposium on, Conference Publications (pp. 389-394). https://doi.org/10.1109/isqed.2000.838902.

Alavi, M., \& Dorothy, E. L. (2001). Knowledge Management and Knowledge Management Systems. Conceptual Foundations and Research Issues. MIS quarterly, 25(1), 107-136. https://doi.org/10.2307/3250961.

Becket, N., \& Brookes, M. (2008). Quality Management Practice in Higher Education- What Quality are we Actually Enhancing? Journal of Hospitality, The Journal of Hospitality, Leisure, Sport and Tourism, 7(1), 40-54. https://doi.org/10.3794/johlste.71.174

Brookes, M., \& Becket, N. (2007). Quality Management in Higher Education: a Review of International Issues and Practice. International Journal of Quality and Standards, 1(1). https://doi.org/10.1108/09684880610662015

Brown, J. S., \& Paul, D. (2001). Structure and Spontaneity: Knowledge and Organization. Managing Industrial Knowledge: Creation, Transfer and Utilization, 44-67. https://doi.org/10.4135/9781446217573.n3

Cios, K. J., Witold, P., \& Roman, W. S. (1998). Data Mining and Knowledge Discovery. Springer US. https://doi.org/10.1007/978-1-4615-5589-6

Clarence, S. L. (2016). Knowledge-building: educational studies in Legitimation Code Theory. Journal Article. Innovations in Education and Teaching International, 53(6), 671-672. https://doi.org/10.1080/14703297.2016.1231751

Cornick, T. C. (1988). Quality management model for building projects. International Journal of Project Management, 6(4), 211-216. https://doi.org/10.1016/0263-7863(88)90004-x. EN - ISO 9001:2000

Fong, Y., \& Wai, B. (2008). Using SERVQUAL to measure users' satisfaction of computer support in higher educational environments. University of North Texas, Denton, TX.

Gold, A. H., Mahotra, A., \& Segars, A. (2001) Knowledge Management: An Organizational Capabilities Perspective. Journal of Management Information System, 18(1), 185-214.

Huber, G. (1991) iOrganizational Learning: The Contributing Processes and the Literatures. Organization Science, 2(1), 88-115. https://doi.org/10.1287/orsc.2.1.88

Hung, R. Y. Y., Lien, B. Y. H., Fang, S. C., \& McLean, G. N. (2010) Knowledge as a Facilitator for Enhancing Innovation Performance through Total Quality Management. Total Quality Management and Business Excellence, 3(1), 425-438. https://doi.org/10.1080/14783361003606795

Huynh, Q. L., \& Lin, Y. L. (2013) Employing Heckman Tow-step Sample Selection Method to Investigate Effect of Knowledge Management Adoption on Firms Performance. International Journal of Business and Management Invention, 2(3), 64-71.

Juha, K., \& Ismo, K. (2002). Quality Assurance View of a Management Information System. Chapter published in Encyclopedia of Information Communication Technology, 691-697. https://doi.org/10.4018/978-1-59904-845-1.ch091

Kevin, L., Roger, G. S., Srilata, Z., Charles, L., \& Adrian, S. C. (2004). Integrating quality management practices with knowledge creation processes. Journal of Operations Management, 22(6), 589-607.

Łukasz, R. (2012). Empirical Analysis of the Impact of Requirements Engineering on Software Quality. Chapter published 2012 in Lecture Notes in Computer Science, 232-238. https://doi.org/10.1007/978-3-642-28714-5_21

Mc, K., \& Patrick, G., (2007). Management Information Systems. Managing with Computers.

Melkas, H., \& Tuomo, U. (2007). Quality Of Data, Information And Knowledge In Technology Foresight Processes. ICIQ. 
Moon, J. T., \& Kevin, C. D. (2010). Customer managed knowledge factories. Business Information Review, 27(2), 94-100. https://doi.org/10.1177/0266382110366675.

Oldfield, B., \& Baron, S. (1998). Is Servicescape Important to Student Perceptions of Service Quality? Research Paper, Manchester Metropolitan University.

Oldfield, B. M., \& Baron, S. (2000). Student Perceptions of Service Quality in a UK University Business and Management Faculty. Quality Assurance in Education, 8(2), 85-95. https://doi.org/10.1108/09684880010325600

Oliveira, O. J., \& Ferreira, E. C. (2009). Adaptation and Application of the SERVQUAL Scale in Higher Education. 20th Annual Conference. https://doi.org/10.1109/iecon.2009.5415420

Pentland, B. T. (1996). Information Systems and Organizational Learning: The Social Epistemology of Organizational Knowledge Systems Accounting. Journal of Management and Information Technologies, 5(1), 1-21. https://doi.org/10.1016/0959-8022(95)90011-x.

Pierce, E., Kahn, B., \& Melkas, H. (2006). A Comparison of Quality Issues for Data, Information, and Knowledge. Emerging Trends and Challenges in Information Technology Management: Proceedings of the 2006 Information Resources Management Association Conference, 17th IRMA International Conference, Washington, DC, USA. 2006.

Punch, M. (1994). Politics and Ethics in Qualitative Research. In N. K. Denzin and Y.S. Lincoln (Eds.), Handbook of Qualitative Research. Thousand Oaks, CA: Sage.

Rowley, \& Jennifer, E. (2007). The Wisdom Hierarchy: Representations of the DIKW Hierarchy. Journal of information science, 33(2), 163-180. https://doi.org/10.1177/0165551506070706.

Saunders, M., Lewis, P., \& Thornhill, A. (2012). Research Methods for Business Students. Edinburgh Gate Harlow, England: Pearson Education Limited.

Smith, S., \& Scott, P. (2010). Creativity, Chaos and Knowledge Management. Business Information Review, 27(2), 118-123.

Stodnick, M., \& Rogers, P. (2008). Using SERVQUAL to Measure the Quality of the Classroom Experience Decision Sciences. Journal of Innovative Education, 6(1), 115-133. https://doi.org/10.1111/j.1540-4609.2007.00162.x

Takeuchi, H., \& Ikujiro, N. (2004). Organizational Knowledge Creation. Creative Management and Development Creative Management and Development, 64-81. https://doi.org/10.4135/9781446213704.n5

Tongchuay, C., \& Prasong, P. (2008). Knowledge Quality and Quality Metrics in Knowledge Management Systems. Proceedings of the Fifth International Conference on ELearning for Knowledge-Based Society, Bangkok Metro, Thailand. https://doi.org/10.1109/fskd.2008.189.

Wiig, K. M. (1997). Knowledge Management: where did it come from and where will it go? Expert systems with applications, 13(1), 1-14. https://doi.org/10.1016/s0957-4174(97)00018-3

Yang, Z., \& Robin, T. P. (2004). Customer Perceived Value, Satisfaction, and Loyalty: The Role of Switching Costs. Psychology \& Marketing, 21(10), 799-822. https://doi.org/10.1002/mar.20030

Zack, M., McKeen, J., \& Singh, S. (2009). Knowledge Management and Organizational performance an Exploratory Analysis. Journal of knowledge Management, 13(6), 392-409. https://doi.org/10.1108/13673270910997088

Zetie, S. (2002). the Quality Circle Approach to Knowledge Management. Managerial Auditing Journal, 17(6), 317-321. https://doi.org/10.1108/02686900210434096 


\section{Appendix A}

\section{System portal}

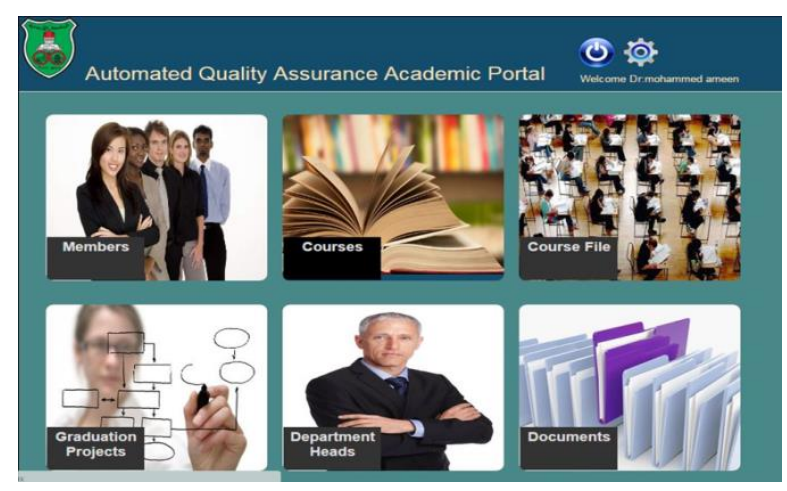

\section{Copyrights}

Copyright for this article is retained by the author(s), with first publication rights granted to the journal.

This is an open-access article distributed under the terms and conditions of the Creative Commons Attribution license (http://creativecommons.org/licenses/by/4.0/). 